\title{
Ground Test Facilities and Integration Concepts for Combat Air Systems at Airbus Defence and Space
}

\author{
Author: Helmut Plankl, Dipl.-Ing. \\ Airbus Defence and Space Test Facilities, Rechliner Str., 85077 Manching, Germany \\ helmut.plankl@,cassidian.com \\ www.airbusdefenceandspace.com
}

\begin{abstract}
European Test \& Telemetry Conference - 2014 in Nürnberg for Session „Methods \& Standards" and will give an actual view on concepts and implementations to improve the efficiency of Ground Test Facilities for Combat Air Systems at Airbus Defence and Space.

First, the presentation starts with a short introduction in the new organisation structure of the Airbus Group. The main part will consider a typical sequence of tests, shows current test assets and facilities and their operation. The presentation will then represent some especially applications at Airbus Defence and Space with the background of qualification of test equipment and to improve the efficiency of Ground Test Facilities in cost, time and risk. An overview on aspects of tool qualification for software verification tools will close the presentation.
\end{abstract}

Keywords: Airbus Group / Airbus Defence and Space / Military Aircraft / Combat Air Systems / Ground Test Facilities / Test Support System / Aircraft Ground Equipment / Integration activities / Test activities / Closed Loop / Tool Qualification / DO-178 / DO-330

\section{Who we are}

\subsection{Airbus Defence and Space}

AIRBUS Defence and Space [1] is a division of the Airbus Group with:

$\Rightarrow$ Airbus

$\Rightarrow$ Airbus Helicopters (former Eurocopter)

$\Rightarrow$ Airbus Defence and Space

In 2012 the Airbus Group had about 140.000 employees and revenues of $€ 56$ billion.

Airbus Defence and Space is built from former EADS divisions:

$$
\begin{aligned}
& \Rightarrow \text { CASSIDIAN } \\
& \Rightarrow \text { Airbus Military } \\
& \Rightarrow \text { Astrium }
\end{aligned}
$$

Airbus Defence and Space is the new home of the group's defence, space and military aircraft business. In these function Airbus Defence and Space is a unique international leader:

$\Rightarrow$ Europe's No. 1 in defence and space and among the top 10 worldwide

$\Rightarrow$ World's No. 2 in space

$\Rightarrow$ More than 40,000 employees

$\Rightarrow$ Approximately $€ 14$ billion in revenue

$\Rightarrow$ Spending more than $€ 3$ billion in R\&D each year

Some of the market leading products are:

$\Rightarrow$ Eurofighter (Combat Aircraft)
$\Rightarrow$ A400M (Military Tiransport Aircraft)

$\Rightarrow$ A330 MRTT (Multi Role Tanker Transport)

$\Rightarrow$ Ariane 5

$\Rightarrow$ ATV (Automated Transfer Vehicle)

$\Rightarrow$ Satellites

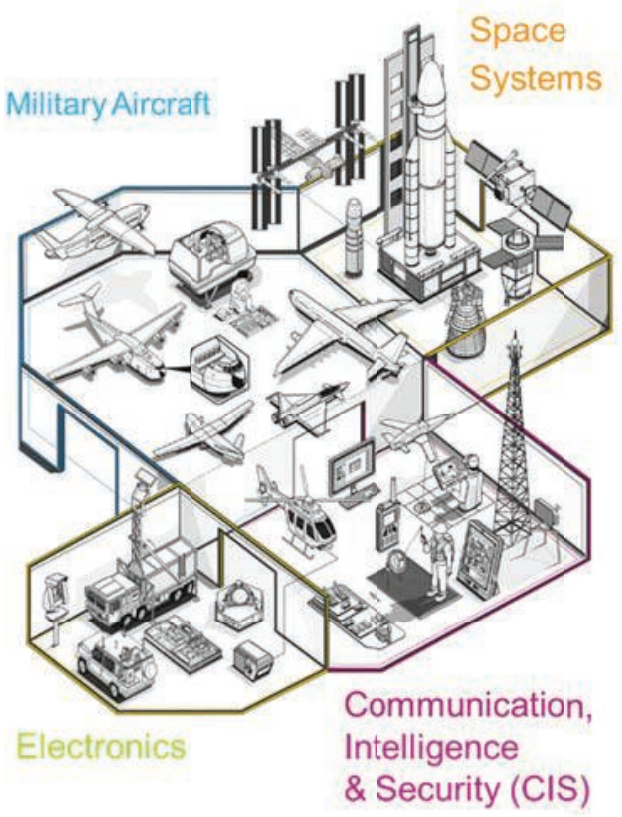

Figure 1:

Airbus Defence and Space: 4 Business Lines Airbus Defence and Space has 4 business lines

$\Rightarrow$ Military Aircraft

$\Rightarrow$ Electronics

$\Rightarrow$ Space Systems 
$\Rightarrow$ Communication, Intelligence \& Security (CIS)

\subsection{Military Aircraft - Test Facilities [2]}

Airbus Defence and Space business line Military Aircraft with its organisational units Flight Test and Test Facilities provide overall expertise in the test concept definition, test program management and execution of rig integration, ground and flight testing.

The "Test Facilities" department for airborne solutions is responsible for the development, design, operation and support of ground test facilities and test support systems, which are used for design validation and verification of civil and military air systems.

Main location is Manching, near Munich in south of Germany with additional locations in Ulm and Bremen. Employees are actually about 180 people

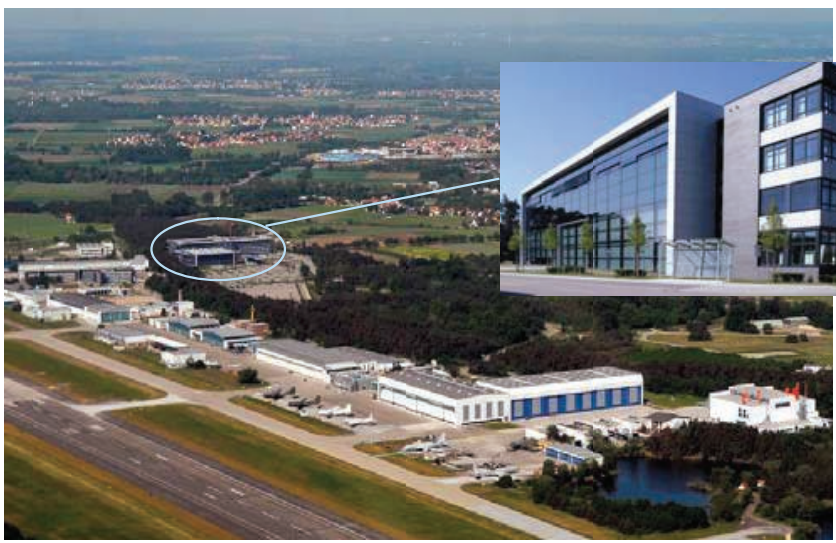

Figure 2: Ground Test Facilities, Flight Test and System Support Center for Eurofighter and Tornado in Manching

Military Aircraft - Test Facilities has following main customers:

$\Rightarrow$ Programs:

$\Rightarrow$ Eurofighter, Tornado, A400M

$\Rightarrow$ Airbus Helicopters: NH90 and Tiger SUZ

$\Rightarrow$ Airbus: A320, A330, A340, A350 Support, A380, MRTT

$\Rightarrow$ Unmanned Air Services (UAS): Barracuda, Talarion, Euro Hawk (Support), Atlante

$\Rightarrow$ Sagitta (Basic research in cooperation with universities and research institutes for UAS)

$\Rightarrow$ Air Forces in Germany, United Kingdom, Italy, Spain, Austria and Royal Saudi Naval Forces (RSAF)

$\Rightarrow$ Training and Support Centers in Germany, United Kingdom, Italy and Spain

We are Tier 1 Supplier for the German military aircraft market.

\section{Test Assets and Facilities}

2.1 Sequence of system test and integration of airborne systems

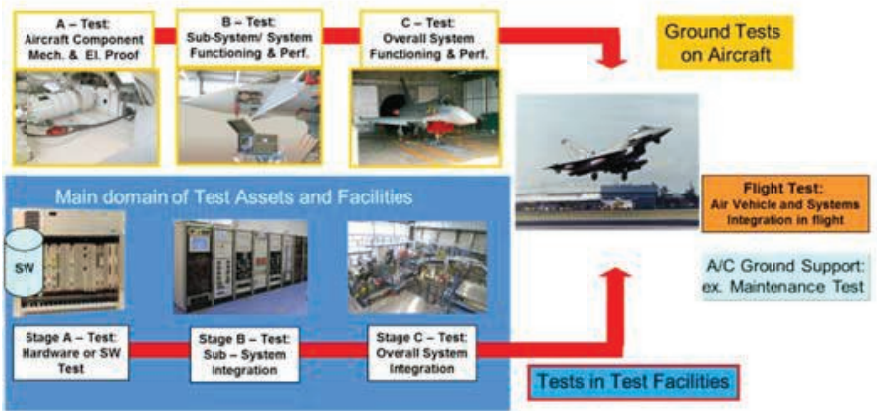

Figure 3: Sequence of system test and integration of airborne systems

\subsubsection{Ground test in Ground Test Facilities}

Stage A Test (Component-, equipment-, software test and test of vendor parts):

Examples:

> Development, debugging and test of new software in a host-computer, who is not necessarily the target-computer

> Test of mechanical components

> Test of hydraulic components (compression force ...)

Stage B Test (Sub-system test, software integration) Examples:

$>$ Software integration benches are used to integrate the software in an aircraft computer (target computer). The software test bench consists of the Unit Under Test (UUT) who is normally the aircraft computer with its functional software, the power supplies, cooling, patch panels, a station to handle and load the software and the test support system. The interfaces to the other aircraft systems and sensor inputs are normally stimulated, so maybe we need some additional actors or signal drivers

$>$ A group of computers has to be integrated as a sub-system

> Test of the electro-hydraulic actuation systems of an aircraft with simulated and stimulated loads

Stage C Tests (System-Integration Tests) are as close as possible to conditions in realistic flight operations with:

> Stimulation of a relevant environment like weight, air loads and sensor inputs for a full system

> Simulation of a realistic flight profile or pilot input

Stage $C$ tests are done on integration facilities who serve to integrate the various systems of the aircraft including:

- Aircraft computers

- Mechanical and hydraulic components

- Sensors and displlays 
Stage C testing is also including Closed Loop Testing or Virtual Flight Test.

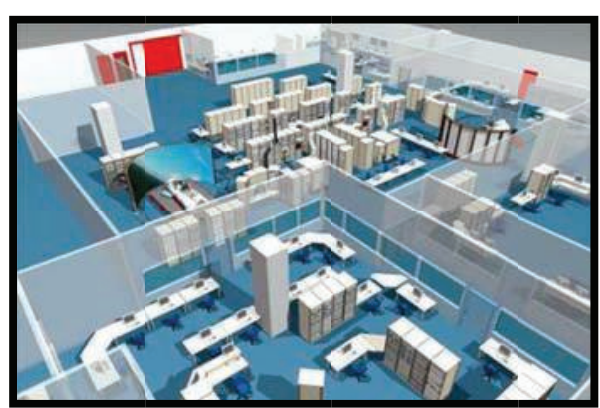

Figure 4: Sequence of Ground Test (from Video)

Test object of ground test in test facilities is:

$>$ Integration of a new system

$>$ Analysing of system-failures

Test steps are including:

$>$ Test under normal and under abnormal conditions

$>$ Robustness testing, to test fail safe functions

All test results must be deterministic!

Why to test this way in Ground Test Facilities?

First reason is some test objects are mandatory by law or certification rules.

Second reason is simple an economic consideration. Goal is to find as many as possible deviations on its root during an early Stage A test, followed by a Stage B test for first integration:

$>$ These are Test in verification- and early validation phases where we normally have manageable functions and clear definitions of responsibilities

Stage $C$ tests however are absolutely necessary but expensive, difficult to manage and detected deviations are very complex and interdisciplinary:

$>$ Practical experience often shows a system may also have a malfunction even if all of its subsystems have passed their individual qualification

$>$ On the other side, some bugs may not lead to an easily traceable malfunction of an "as like as" airborne system, because aircraft systems are highly redundant

Remark: The designations Stage A-, B-, C tests are called level 2, 1 or 0 tests on some other technology domains.

\subsubsection{Ground test on Aircraft}

Stage A test:

\footnotetext{
$>$ Assembly tests

$>$ Tests of wiring, connectors, electrical isolation...
}

Stage B test:

System tests with aircraft on external electrical power- and hydraulic supply

\section{Stage C test:}

$>$ System Tests with running engines

Test object of ground test on aircraft is:

$>$ Integration of a new system into the aircraft

$>$ System is safe (and finish for flight test)

\subsubsection{Flight Test}

Test object of final flight test is certification and qualification of a system on the airborne platform, including all mission-, operation- and safety aspects.

\subsubsection{Aircraft Ground Support}

A typically test of on aircraft in service is test within maintenance.

\subsection{Competencies in Test Assets and Facilities:}

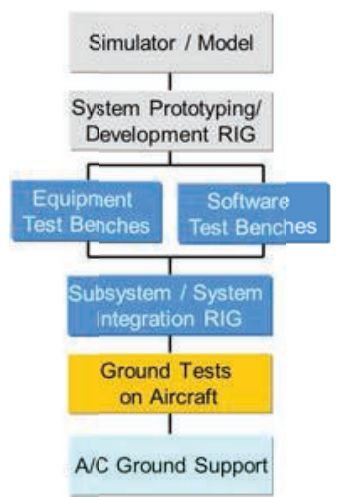

Figure 5: Fields of Applications

Ground Test Environment will be developed for:

$\Rightarrow$ Pre-engineering and prototyping

$\Rightarrow$ Aircraft systems

$\Rightarrow$ Fault simulation on aircraft systems

$\Rightarrow$ Acceptance tests for aircraft computers

$\Rightarrow$ Problem analysis and verification

$\Rightarrow$ Software maintenance

$\Rightarrow$ Software modification and upgrades

$\Rightarrow$ Integration of new capabilities

$\Rightarrow$ Aircraft maintenance and flight line support with Aircraft Ground Equipment (AGE) 


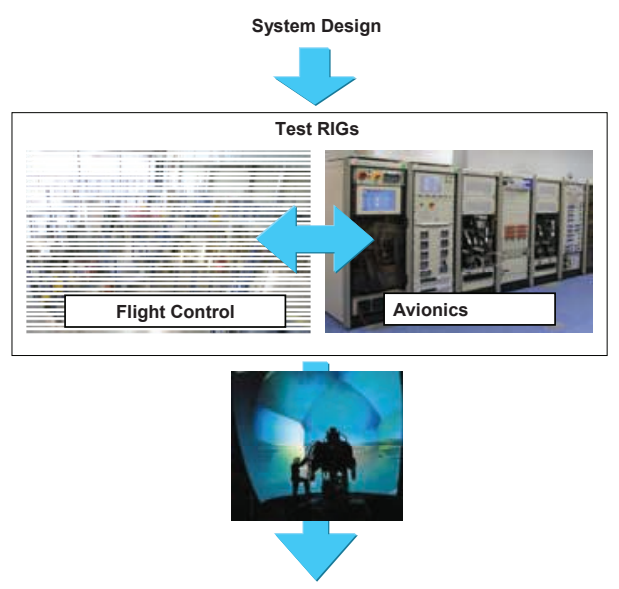

Figure 6: Competencies

Competencies for Test Facilities at Airbus Defence and Space are:

$\Rightarrow$ Analysis of aircraft- and test requirements

$\Rightarrow$ Specification and design of test facilities

$\Rightarrow$ Development and production of test equipment

$\Rightarrow$ Integration into overall system

$\Rightarrow$ Qualification and certification

$\Rightarrow$ Product- and user-support

$\Rightarrow$ Maintenance, repair, upgrade (of test facilities) including obsolescence handling and technical safety

$\Rightarrow$ Configuration and operation of test facilities

Test Assets and Facilities are for:

$\Rightarrow$ Avionics incl. navigation, sensors and displays

$\Rightarrow$ Flight Control Systems (FCS)

$\Rightarrow$ Landing gear

$\Rightarrow$ Hydraulic

Overall system availability and cross-linking ability lead to Closed Loop testing at Airbus Defence and Space with hardware in the loop and pilot input. In these operation modes replay of flight data and ground test against flight data is a great thing. You see it's a great need to continue harmonisation of the data formats between flight- and ground test.

\section{Applications to improve efficiency (cost, time and risk) of Ground Test Facilities}

\subsection{Test Facilities Operation}

Test facilities are high investments because of the costs of test assets and also because of the need of original aircraft components. Operation, maintenance and obsolescence handling are other expense factors.

Improvement of efficiency of test facilities operation, maintenance and support will be demonstrated using the example of the German "System Unterstützungs
Center" (SUZ). The SUZ in Manching provides support capability for the full range of Tornado and Eurofighter's needs in cooperation between the German Air Force from national customer side and Airbus Defence and Space from engineering and industry side. Tasks of the SUZ are:

$\Rightarrow$ User help desk for the German Air Force

$\Rightarrow$ Problem verification, analysis and solution

$\Rightarrow$ Software update and changes

$\Rightarrow$ Training of system engineers (for Eurofighter only)

$\Rightarrow$ Expansion for Eurofighter export customers or for other technology like UAS is possible

Cooperation and common use of the SUZ will lead to significant cost savings. Sharing of resources and upscale (high cost) components like radars, complex test equipment or simulators are clear benefits of the common use of the test facilities.

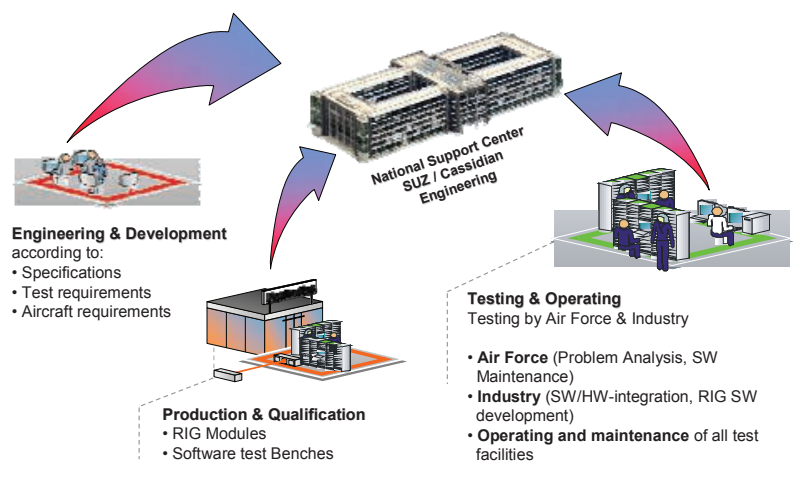

Figure 7: Cooperation between Airbus Defence and Space and German Air Force in SUZ

Facts (Eurofighter +Tornado) (2013 about):

Stage A and SW Test Benches:

Stage B and Subsystem Rigs:

42

Stage $C$ and System Integration Rigs:

Test Support Systems:

65

(About 500.000 Parameter for Eurofighter)

LRI under Test:

1330

Aircraft Configurations under Test:

Customers (Persons):

500

\subsection{Tool based rig management and control}

Customers expect full operation of the system under testing conditions and the whole handling of the Units Under Test (UUT) meets their requirements (e.g. power distribution, avoiding of electromagnetic distortion and provision of cooling). Set-up times are also cost factors and to be kept to minimum. Fully configuration control is indispensable.

For this, additional management and control tools are supporting the test facility in achieving an ideal 
workflow and to keep configuration permanently under control. Additional the tools are used for the preparation of tests and for reporting the test results.

TRAC (Test RIG Allocation and Control) is for Test preparation and planning activities including:

$\Rightarrow$ Test shift planning

$\Rightarrow$ Configuration control of hardware and software

- Continuous monitoring of configuration

- Status of available hard- and software

- Storage and back track of equipment

- Status of all previous test runs

$\Rightarrow$ Administration of technical documentation and procedures

When a test shift is initiated, TRAC is responsible to initiate and support the following steps in preparation of a test shift:

$\Rightarrow$ Preparation and configuration control of the test environment for the test shift:

- Test procedures

- Manual rig configuration or optional automatic configuration of the test facility with the Rig Control Center (RCC) by a Patch Matrix Module (PMM)

$\Rightarrow$ Preparation and configuration control of the Units Under Test (UUT) (hardware \& software)

$\Rightarrow$ Preparation and configuration control of all technical documentation

TRAC in the post phase of a test is used for:

$\Rightarrow$ Support of test report generation

$\Rightarrow$ Handling of problem reports and change requests

Common tasks of TRAC are:

$\Rightarrow$ Monitoring and control of business activities in the Product Quality Assurance Process

$\Rightarrow$ Quality assessment certified process statistics

$\Rightarrow$ Statistics for test facility efficiency

The RCC supports the operation and maintenance of test facilities and provides a fast overview of essential rig functions.

On some Eurofighter applications when invest is reasonable the RCC can also configure the power distribution modules and the PMM for electronic patching of complete modules comprising MIL-1553, optical data links, analogue/discrete, video etc...

On some other cases a Radio Frequency Identification System (RFID) is just in implementation to inspect if the right components are on the right place. This is for configuration control and for example to protect some hardware from risk of damage by wrong power distribution if no other means like a mechanical code or read back of configuration data by software is possible.
In order to maximise the efficiency of the test facilities, therefore, an integrated tool set is absolutely vital. The combination and interaction of TRAC, RCC, PMM, RFID and of course the Test Support System AIDASS $®$ (Advanced Integrated Data Acquisition and Stimulation System) or MaTE (Modelling and Test Environment) increases efficiency and improves the quality of the process that operates the test facilities.

\subsection{Interaction between TRAC, RCC, PMM and RFID in Eurofighter SUZ}

You should consider we do not test one aircraft; we are testing for example Eurofighter Tranche 1, 2 and 3 as single- and as a twin seater, with some variations of 6 nations. We make tests for engineering, for actual certification, for retests and for failure investigation on systems already in operation.

Setup, operation and configuration control on such large test facilities with multiple users like the Eurofighter SUZ cannot be a manual process, as this is simply not safe and not fast enough. It requires the right set of tools to support the complete process.

That allows resources to be shared and multiple test sessions to be run at the same time in a multiple rig test facility. TRAC in combination with the RCC and PMM enables set-up times and maintenance downtimes to be kept to a minimum. RFID helps to prevent of some remaining risks.

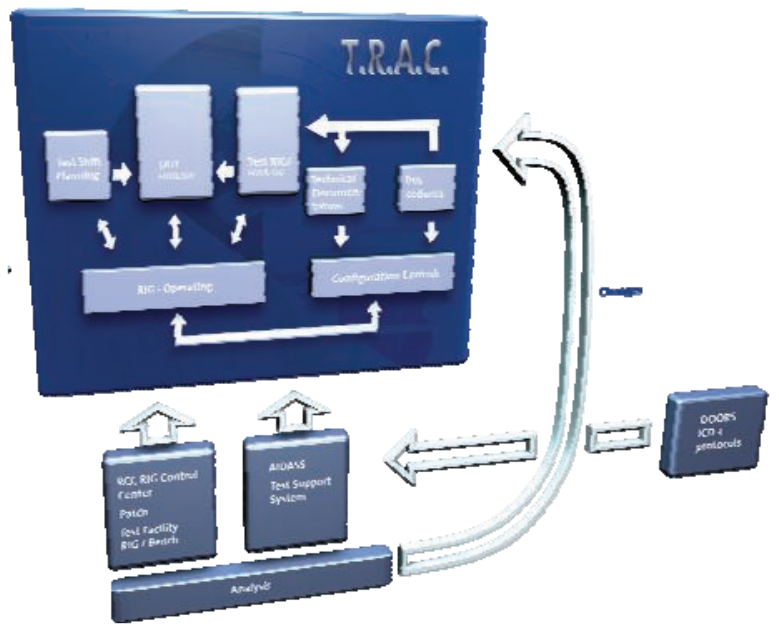

Figure 8: Interaction between TRAC, RCC, PMM

$\Rightarrow$ It is important to transfer the information of shift planning from TRAC to the RCC to ensure a defined setup of the test facilities

$\Rightarrow$ Any failure or change of the configuration of a formal test shift should be detected and will affect a note in the configuration report 
$\Rightarrow$ Equally important is to supply all relevant data to ensure correct execution of the Test Support System (AIDASS or MaTE)

$\Rightarrow$ Monitoring and control of business activities is also a condition for fair cost division

Actually we are able to handle 19 Eurofighter configurations in 3 system integration rigs with one of these as a fully Closed Loop or Virtual Flight test.

Formal Tool Qualification is another argument. TRAC, RCC, RFID and PMM are embedded in the company certification process.

\section{Tool Qualification Considerations}

Aircraft systems and other safety-critical technology must be consistently supported by a product quality assurance process throughout the product life cycle. Any deviations from the software plans and standards must be detected, recorded, evaluated, tracked and resolved. Approved deviations must be documented and recorded.

Aspects of Tool Qualification for development and integration of airborne software (and as well as for hardware) must be considered consistently.

$\Rightarrow$ Need for Tool Qualification is clearly defined in DO-178C [3]

$\Rightarrow$ Tool Qualification Supplement DO-330 [4] contains objectives, activities and life cycle for the whole tool development life cycle

Remark: This section 4 is a rough estimation and only for an overview and justification of need of tool qualification. Detailed criteria are to find in DO-178C / DO-330 and in additional formal documents and also in certification authority regulations.

\subsection{Criteria for Tool Qualification}

A. Tool Qualification has to be considered, if answer of both questions is "Yes":

$\Rightarrow$ Are Processes of DO-178C eliminated, reduced or automated by the use of the tool

$\Rightarrow$ Will the output of the tool not be verified or conformed by other verification activities as defined in DO-178C

\section{B. Determining the criteria for Tool Qualification:}

Verification Tools like Ground Test Facilities and Test Support Systems normally have to be developed and qualified under consideration of criteria 2 or 3 . These are tools within the scope of its intended use, could fail to detect an error, but cannot insert a failure in airborne software.
More severe criteria 2 is equipment that is in addition designed for complex automatisation of verification processes.

Criteria 1 however is a tool whose output is part of the resulting software (or Hardware) and thus could insert an error. This can be a software development tool for airborne software who can introduce failures in airborne Software. Verification tools are normally not to be considered as criteria 1 tool.

C: The Tool Qualification Level (TQL) is dependent from the criteria for Tool Qualification and the Design Assurance (DA) Level of the unit or system under test.

\begin{tabular}{|c|c|c|c|}
\hline $\begin{array}{c}\text { Software DA } \\
\text { Level } \\
\text { (System/ } \\
\text { Sub-system/ } \\
\text { Unit Under Test) }\end{array}$ & \multicolumn{3}{|c|}{ Criteria for Tool Qualification (TQ) } \\
\cline { 2 - 4 } DAL-A & Criteria 1 & Criteria 2 & Criteria 3 \\
\hline DAL-B & TQL-2 & TQL-4 & TQL-5 \\
\hline DAL-C & TQL-3 & TQL-5 & TQL-5 \\
\hline DAL-D & TQL-4 & TQL-5 & TQL-5 \\
\hline
\end{tabular}

Figure 9: Determination Table for Tool Qualification Level (TQL)

\subsection{Activities for tool qualification for software verification tools}

Qualification of a verification tool is always together with verification of the airborne system.

The Plan of Software Aspects of Certification (PSAC) for the airborne system should include the intended tool qualification schedule: A listing of all software tools and justification for why each tool does or does not require qualification.

Key activities for qualification of a new tool (TQL 4 and 5) or for reuse or modification of an existing tool in a new program are for example:

$\Rightarrow$ The PSAC

$\Rightarrow$ A tool qualification plan

$\Rightarrow$ Configuration management and quality assurance processes over the whole tool qualification process - and then later over the whole tool lifetime (see my chapter 3)

$\Rightarrow$ Demonstration of tool operation and tool verification records

$\Rightarrow$ A problem reporting

$\Rightarrow$ Some monitoring and control activities have to be done by an independent organisation

Product service history for tools already in similar projects or experience in a trial period may support this process. 
Additional independency like RFID or read back of software configuration can help to reduce the TQL of a complex test facility.

\section{References}

[1] AIRBUS Defence and Space, one mission. One team, one direction / March 2014

[2] COEMT - Test Facilities: "Master Presentation" / 2014

[3] RTCA: "DO-178C Software Considerations in Airborne Systems and Equipment Certification", 2011

[4] RTCA: "DO-330 Software Tool Qualification Considerations", 2011

(

\section{Author/Speaker}

Helmut Plankl has more than 25 years of experience in the field of system design verification and validation, technical problem solutions and aspects for continuous product and process improvement.

$\mathrm{He}$ is responsible for technology projects to improve economy and efficiency of Ground Test Facilities for civil and military air systems.

As expert in the field of electrical and fibre optical communication systems, he is inventor of some relevant patents and participant on global standardisation teams.

$\mathrm{He}$ is auditor for Quality Management Systems up to DIN/EN 9100. 